\title{
Analysis of 'Flat-Earther' Posts on Social Media: Reflections for Science Education from the Discursive Perspective of Foucault
}

\author{
Leonardo Wilezelek Soares de Melo ${ }^{\circledR}$ Brazil \\ Marinez Meneghello Passos ${ }^{(1)}$ Brazil \\ Rosana Figueiredo Salvi ${ }^{(1)}$ Brazil
}

In this paper we present the results of a research that aimed to analyze posts on a Twitter page of an organization that openly defends that the Earth is flat and to highlight its formative characteristics, as well as to discuss about the possible implications of such defense for Science Education. Discourse analysis was carried out based on the guidelines presented by Foucault and $a$ priori theories were taken from the contributions of Feyerabend, Latour and Stengers. These choices occurred due to the fact that these contributions present heterodox points of view on the production of scientific knowledge, open to implications that are not only epistemological, which makes it possible to discuss the cultural, social and discursive complexity of the 'flat Earth belief'. It is hoped that the considerations presented here may promote discussions related to the theme on the part of those who work in Science Education and, also, promote reflections on the very ethics of the scientific process and its limits.

Keywords: social media; flat Earth; discourse analysis.

\section{Introducing the research}

In times of post-truth (Dunker et al., 2017), scientific consensus, once considered indisputable, is put in check by certain groups and institutions, through propagation dynamics known as conspiracy theories. These have gained more and more space in the discussions and agendas of the most diverse fields of knowledge, a scenario that has mobilized us to investigate the action of one of these expanding phenomena. Therefore, in this paper, we bring the results of a movement that highlights the implicative nuances of one of its aspects - the hypothesis that the Earth is flat - for Science Education.

This situation led us to describe, briefly, some details about these conspiracy theories (which support discourse in a multidisciplinary way), passing through Psychology, Psychiatry, Communication, Linguistics, Anthropology and even the Philosophy of Science. In view of this delimitation, we consider a conspiracy theory to be any narrative or plot that accuses certain groups of people or organizations, which are most of the time powerful and in some cases mysterious, to come together to work, secretly, usually for malevolent goals (Goertzel, 1994; Wood, Douglas, \& Sutton, 2012; Swami et al., 2014; Prooijen, 2017). However, this definition is neither sufficient 
nor closed in itself, since there are a multiplicity of discourses that can be judged by conspiracists and have their own particularities.

Among the various existing 'types' of conspiracy theories, these can be listed, among others, as: those of a political-international nature, such as those that discuss suspicious factors involving the September 11, 2001 attack, the deaths of John Kennedy, Princess Diana or Bin Laden (Harambam, \& Aupers, 2014); those of a socioeconomic nature, related to the migration of certain ethnic groups to European countries or the United States of America and the domination of powerful elites in Latin American countries (Silva, Vegetti, \& Litvayy, 2017); those that cover rumors related to Science and Technology, among which stand out those that claim that vaccines cause autism, those that argue that climate change is nothing but deceptive gossip (Jolley, \& Douglas, 2014), or even those that consider that the Earth is flat (Prooijen, \& Douglas, 2018).

Increasingly growing and dispersed throughout society, enhanced by the advent of digital and social media, the strategies to understand or deal with these conspiracy and controversial theories have been mostly reactive, focusing on labeling and oppressing the discourse, defending political, social and economic impositions to the groups that support these conspiracy theories. In addition, little has been thought proactively about the theme, with the majority of positions that attempt to modify such behaviors and attitudes of the denial of Science, taking as a basis their own scientific knowledge and their standards of rationality, as discussed by Browne et al. (2015), with minority attempts to conceive this phenomenon in its cultural and discursive complexity.

Considering this problem, we look at the posts on the official Twitter page of an organization that openly defends that the Earth is flat, using qualitative analysis theories to analyze the discourse: the theoretical contributions of Foucault (1996). Expanding, we also bring discussions about the possible implications of this discourse for Science Education (our area of expertise), as well as about its structure and characteristics, taking as theorizations for this analysis the contributions of Feyerabend $(1977 ; 2010)$ and of Social Studies of Science, based on the discussions promoted by Latour (2004; 2011) and Stengers (2015). Such points of view, in terms of the Philosophy and Social Studies of Science, were considered coherent with the objectives set forth here, in terms of their criticisms of scientific orthodoxy and strict rationality, in the first author's case, and the ways of production of scientific facts, in the second auhor's case.

In view of this purpose, two questions were considered guides and can be revisited as follows: From these perspectives, what understandings could be demonstrated from the discourse evidenced in the analyzed Twitter publications, considered 'conspiracists' and that claim that the Earth is flat? What positions could the field of Science Education put together in the face of these discourses?

In order to proceed with the proposed arguments, the discussions were structured on the following four topics: addressing the main ideas about what has led people to believe in conspiracy theories such as that the Earth is flat; presenting the methods used in the research and the references that support them; presenting and analysing 
the research data collected on the Twitter page of the organization that defends the 'flat Earth' theory; and presenting the considerations obtained after the structured analyzes and reflections, so as to discuss the conceived impressions referring to the discourses that evoke that the Earth is flat and the paths that the analysis of these discourses show in relation to Science and its teaching.

\section{A complex question: why do people believe in conspiracy theories?}

Before building a discussion in relation to the question that entitles this section, it must be noted that conspiracy theories are not necessarily false by definition (Wood, Douglas, \& Sutton, 2012), and are often originated from the analytical capacity of subjects to criticality infer about certain political or governmental actions and the existing asymmetry in power relations in society (Pelkmans, \& Machold, 2011). In certain cases, they can even generate advantageous social consequences, such as encouraging citizens to be more questioning of their politicians and government officials, leading to greater government transparency (Douglas et al., 2016). These observations need to be well demarcated in this context of discussion, without thereby arguing that these theories are coherent or plausible. This leads us to maintain that there should not be a single and conclusive answer that can explain what has led people to believe in conspiracy theories.

That said, some positions can be presented. Prooijen and Douglas (2018) highlight four possible basic principles for the acceptance of these theories: consequential; universal; emotional; social. The first reason is that even if a conspiracy theory is naive or supposedly difficult to believe, the simple belief in it can impact people's health, relationships and safety, since it can induce real behaviors, such as non-adherence to vaccination. The second principle - universal - suggests that there is no specific historical or cultural dimension to the beliefs in conspiracy theories, as everyone can be susceptible to them, even accepting that this is a characteristic of human nature. The third principle - emotional - indicates that the belief in conspiracies can be associated with intuitive and non-analytical mental processes rooted possibly by negative emotions and automatic thoughts. The fourth principle - social - defends that the belief in conspiracies is a social phenomenon, since it involves not just an individual, but in general a collective that often shares the same fear towards a certain organization or social group.

Regarding this last principle, Wood, Douglas and Sutton (2012) argue that, even if a certain conspiracy theory is contradictory in relation to any other, people can still believe in both, without seeing the possibility of an inconsistency. Which can be explained by the fact that what brings such beliefs together is not necessarily a link between theories themselves, but higher order understandings regarding them, such as feelings of distrust towards authorities or governments, that are in the discursive center and that connect several of these conspiratorial beliefs.

Similarly, Prooijen (2015) argues that conspiratorial beliefs can arise from similar underlying psychological processes and be influenced by two complementary factors, 
called "subjective uncertainty, and a social concern for others" (p. 267). The first would be related to the existence of a feeling of marked uncertainty regarding certain events that are often complex, which incites the subject to promote processes that help him/her to understand these events. This would be consistently aligned with the idea that such beliefs usually flourish after events of great social impact, with the processes involved in proposing these theories a means of placing order and predictability in perceptions about the events. On the other hand, the second would be related to the support to the groups affected by any of these events of great impact, this support justified in view of the supposed or possible attacks of the "powerful" who would be behind these events, through such theories. Prooijen (2015) points out, in this sense, that strong feelings of collective inclusion may be characteristic of certain conspiratorial beliefs.

Douglas et al. (2016) point out that belief in conspiracy theories may be associated with the way people perceive the world around them and how they deal with events that appear to be uncertain or obscure. This may be related to the tendency of certain people (or groups) to attribute intentionality and action to cases in which they are unlikely to exist, as occurs in automatic judgments regarding the occurrence of certain phenomena that seem supernatural. In these cases, the view is that this is not necessarily a negative trend, since it can be rooted in the very evolution of the human being, who has always had to show the ablility to react quickly to ambiguous and strange situations, coming from the environment, a factor that was important for the physical and social survival of the species.

Allied to what these authors discuss, Prooijen (2017) points out that people with higher educational levels are, in theory, less susceptible to believe in conspiracy theories, although this must be sustained with caution, since the relationship between educational level and belief in conspiracies is "the product of the complex interplay of multiple psychological processes" (Prooijen, 2017, p. 56). Thus, even feelings of social impotence in the context in which they live can imply the acceptance of these theories, and this relationship should not be defended in a simplistic way, nor as a valid motivation to question or interfere in the beliefs of these people.

A characteristic common to all conspiracy theories, even in the case of untrue ones, is the fact that they have a significant resistance to any attempts of contradiction proposed by their critics or skeptics. Such theories may constitute a "degenerating research program" (Wood, Douglas, \& Sutton, 2012, p. 767), in which their "theorists" appeal to new conspiracy evidence that is added to the original theory in order to validate their intentions and, therefore, reaffirm them.

This resistance to the impugnation on the part of followers of conspiracy theories allows us to infer that attitudes that are always judging or denouncing towards their followers may not have any effect in the sense of discouraging them, since the labels placed by critics are usually more effective in denigrating the people considered 'conspiracists' than the theories themselves. Furthermore, on the other hand, such accusatory attitudes may even reaffirm these beliefs and encourage their followers to question whether, in 
reality, such theories are acting in the right direction (Wood, 2016).

This can be corroborated by the discussions carried out by Browne et al. (2015), who question the effectiveness of measures based on scientific rationality, as well as on evidence-based reasoning, among them the majority of the strategies for dealing with positions that refuse Science. Such measures would not take into account an important factor studied by Cognitive Psychology: "Humans are biased information processors and often engage in motivated reasoning" (Browne et al., 2015, p. 01). This allows us to hypothesize that emotional and social factors may be more decisive on human reasoning and on daily decision-making, imposing certain inaccurate prejudices and heuristic biases that would not, by obligation, be apt to change just by presenting proven empirical facts and evidence of Science, which denotes the cultural complexity linked to these beliefs.

It is in this sense that our curiosity and our investigative sense for understanding the discourses, present in publications of a Twitter page, considered as conspiracy and which openly defends the hypothesis that the Earth is flat, emerges. Therefore, we seek to go beyond its linguistic and textual structure, analyzing its discursive character as a practice, as assumed by Foucault (1996), in order to cover its intrinsic regularities and define the conceptual networks that are its own.

It is worth noting that, through this discursive perspective there are no truths behind the discourses awaiting revelation by an analyst, but statements and articulations put into practice by the discourse itself. We propose that assuming this conjuncture can help in understanding the cultural complexity linked to conspiracy discourses such as of the flat Earth, which may have emergence and diffusion associated with issues that go beyond their theorizations, as well as supposed demands for rationality on the part of their followers. In the next topic, we outline the methodological guidelines we took to proceed with this investigation.

\section{The methods in action}

In this research process, we sought to investigate the Twitter page of the international organization, the Flat Earth Society, which produces and shares content based on the conspiracy theory that the Earth is flat, and which currently presents considering the year 2020 - thousands of followers, being the most accessed page on the theme, according to research results related to the theme on Twitter. The content of the page's tweets is quite diverse, ranging from images and "memes" referring to the theory of the Flat Earth to the dissemination of content and events related to this theory, in addition to various criticisms of modern scientific knowledge.

For the delimitation of the corpus ${ }^{1}$ of the research, initially the content related to one year of posts on the page was selected, between the months of May 2018 and May 2019, which only the posts with content produced by the Flat Earth Society's own profile

1 “[...] the set of documents taken into account to be submitted to the analytical procedures" (Bardin, 2011, p. 126, our translation). 
were collected, excluding those that were produced by other profiles or other people and that were only reposted by the organization's page.

Afterwards, posts that did not contain information considered relevant for the purposes of analyzing the discourse of the 'flat-Earthers' were discarded, including tweets that contained greetings, or that shared information that did not explicitly deal with the theory of the Flat Earth in its content. These initial delimitations and discards made it possible to gather a total of 20 tweets, which included texts and phrases, some dialogues with other profiles and people, in addition to "memes" about the theme. Of the 20 tweets, posts that made some kind of reference to other profiles or people were discarded, because in these cases broader and more diverse discussions were triggered, involving attitudes and points of view not necessarily related to the hypotheses of flat Earth - including the emergence of personal attacks between profiles.

After these delimitations, 8 tweets remained, interpreted based on discourse analysis, according to Foucault (1996). For this author, the production of the discourse "is at the same time controlled, selected, organized and redistributed by a number of procedures that have the function of conjuring up its powers and dangers, dominating its random event, avoiding its heavy and fearful materiality" (Foucault, 1996, p. 08, our translation). In other words, every discourse is produced from power relations. In this context, "the discourse is not simply that which translates the struggles or systems of domination, but that because, for what one fights, the power that we want to seize" (Foucault, 1996, p. 10, our translation).

In this context, as highlighted by Fischer (2001), "everything is practical in Foucault" (p. 200, our translation), and everything is immersed in relations of power and knowledge. It is in this sense that the discourse goes beyond its use as a mere expression of things and consolidates itself as a conceptual network with its own characteristics. The formation of concepts, therefore, would not be in the consciousness of individuals, following standards of rationality, but in the discourse itself, and the rules of discursive formation "are imposed on all those who speak or try to speak within a given discursive field" (Foucault , 1986, p. 70, our translation). This perspective was considered coherent to analyze the context of the controversy in which the conspiracies are inserted, which seek to oppose the scientific knowledge established from the elaboration of discordant hypotheses and, to some extent, hostile to modern Science and its institutional hierarchy, even if, for such dissonance, they start from ideas that are often inconsistent and illogical.

This peculiarity of the discourse, according to Foucault (1996), and in our scope of discussion, can be related to the arguments promoted by Feyerabend (1977; 2010) in relation to the search, by scientists, for the universalization of the rules that would constitute the scientific method, an action that, according to the author, can be consolidated as a kind of dogmatism, which would fulfill the function of legitimizing the scientific process and disqualifying ideas that would not be aligned with its assumptions. If, for Foucault (1996), the discourse is a practice immersed in relations of power and knowledge, and that is instituted for all who participate in a determined 
discursive process, for Feyerabend (2010), scientists would seek to universalize the rules that constitute the scientific method - and that, in short, constitute their discourse -, using all possible means and tools, such as "argument, propaganda, pressure tactics, intimidation, group action" (Feyerabend, 2010, p. 341, our trnalsation), in order to reiterate its strength in society, undermining other forms of knowledge that do not agree with its considerations.

However, in the context of conspiracies, this relationship becomes somewhat more entangled, since, at this juncture, conspiracy discourses, as already presented, have been consolidated from the generalized mistrust in Science, pointing to a supposed global and malevolent plot, of which Science, researchers, industry sectors and governments would be a part of. According to these conspiracies, such agents would have the supposed intention of deceiving and controlling people and society (Prooijen, \& Douglas, 2018). However, differently from what we might expect, these conspiracists, instead of giving up the controversy, or adhering to scientific propositions, as noted by Latour (2011), have been steadfast in supporting them, even if they lack discursive power in the face of the expressive power of Science and are ridiculed by the media, institutions and the general public.

What moves us in methodological terms is to discuss what could be keeping conspiracists firm in effervescing the revisionisms that they insist on nurturing - even against data and expectations. Would this insistence of denying Science be a product of dogmatism itself of an authoritarian Science, discussed so much by Feyerabend (1977), having so concentrated on universalizing its methods and rules, have forgtton those who would not understand it or would resign from it? Or is this an incongruous phenomenon in relation to the criticisms promoted by Feyerabend (1977) against scientific orthodoxy, and which would require new perspectives beyond epistemology - even the heterodox?

To more than suspect, we tried to conduct an analysis that did not have as a principle to make mere theoretical judgments in the face of discursive 'flat Earth' manifestations, nor beforehand to qualify them as alienated or even insane and bizarre in some sense - although it is tempting to do so. In addition to judgments or prognoses, we seek, based on the assumed methodological contributions, an understanding of these phenomena in their cultural and discursive complexity, and Foucault's (1996) discursive perspective is inviting in this sense.

It is worth noting, at this moment, that there are certain principles of social exclusion linked to the production of discourses in society, considered by Foucault (1996), which we can bring up to continue with our intentions. As the author argues, the systems are: the forbidden word; the segregation of madness; and the will to truth, the last two being of greatest value to our investigative purposes.

As Foucault (1996) points out, the segregation of madness, common in the Middle Ages, as a social marker of impediment and disqualification of discourses, is still present, occurring, today, by other means, by other institutions and producing other effects, but with the same intention of separating the discourse that must be considered 
acceptable and that which must be stopped and qualified as undesirable. The will to truth, on the other hand, results from the fluidity to which the notion of truth is organized, and which is sustained, almost always, from a certain degree of pressure and violence. When analyzing the institutionalization process of what is considered true in the course of history, it is highlighted that, for the author, there is no question of a discussion about what is real and what is not, but only the means and modes by which they consolidate.

What we intend with this theoretical perspective is to avoid the immediate exclusion of the 'flat Earth' speech, without first understanding its terms, its formation and its own complexity.

Perhaps the great challenge of a perspective like this lies in how to proceed to understand the phenomenon of conspiracies in a symmetrical way, as supported by the Social Studies of Science and Technology, without the promotion of derogatory judgments, and, at the same time, without appearing to be considering its theorizations potentially reliable. This perspective of symmetry, which Stengers (2015) presents as the act of not qualifying winners and losers before the end of a controversy, can cause some discomfort when evaluating, from an orthodox epistemological perspective, such a controversial context, as it is the case of conspiracies. However, he is congruent with the intent to talk about this controversy without constituting the scientific dogmatism that Feyerabend (1977) had so warned about, and yet, being consistent with Foucault's (1996) discourse perspective.

Under these parameters, therefore, we analyze the data obtained from the Flat Earth Society page, which are presented and discussed in the following section.

\section{The data and its evidence}

The selected tweets that make up the corpus of the analysis are shown in Figure 1, in the first column. To represent each tweet, we created a code beginning with the letter T accompanied by a number that is related to the tweet's layout in the frame - second column. In this way, tweet 1 was represented as T1, tweet 2 as T2 and so on. In addition, the date of publication of the discourse presented on the twitter page is in column 3 . The discussion did not necessarily take place according to the chronology of the tweets in Figure 1, but we consider their relevance for the argumentative moment.

T1 and T5, tweets of October and December 2018, respectively, classified as "memes", which, as Shifman (2013) points out, are types of information units that propagate efficiently through communication between people, each being increasingly recurring in digital media communication, used by users for quick absorption and dissemination of content. In the first of these, on the label of a milk carton, there is a "DISAPPEARED" ad, in reference to the curvature of the Earth. The second of these features a phrase printed on a T-shirt worn by an unidentified woman: "I ONLY DATE FLAT EARTHERS”. 


\begin{tabular}{|c|c|c|}
\hline Tweet & Code & Date (m/d/yyyy) \\
\hline 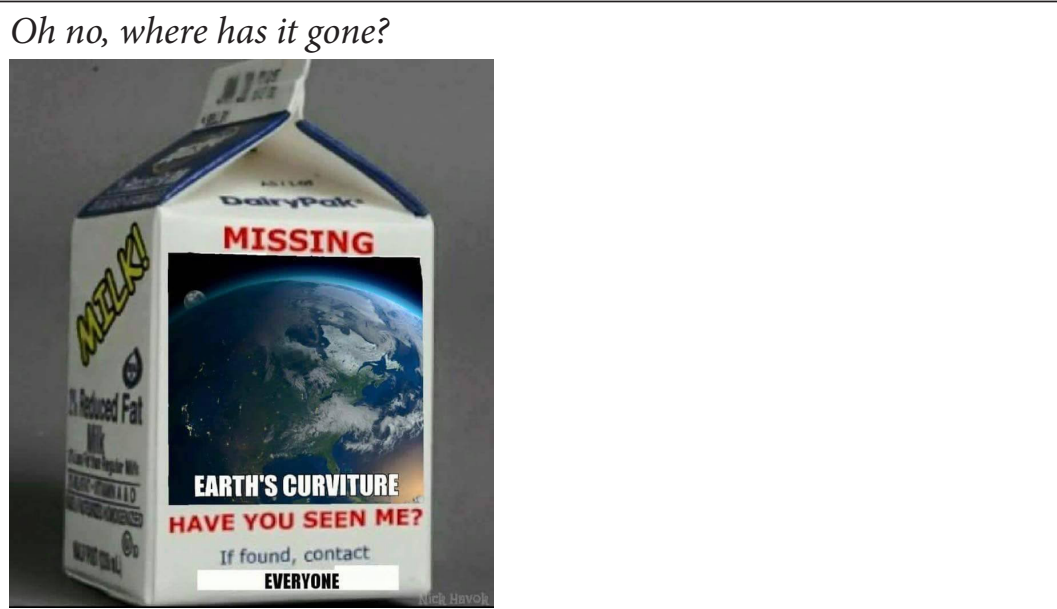 & $\mathrm{T} 1$ & $10 / 09 / 2018$ \\
\hline $\begin{array}{l}\text { \#EverybodyShouldGet informed on the simple fact that the Earth is } \\
\text { flat }\end{array}$ & $\mathrm{T} 2$ & $10 / 23 / 2018$ \\
\hline $\begin{array}{l}\text { The Earth is not round. } \\
\text { \#StartOverIn5Words }\end{array}$ & T3 & $10 / 23 / 2018$ \\
\hline $\begin{array}{l}\text { Ah, the smell of indoctrination in the morning! } \\
\text { These are children who struggle to spell the word "think", but they've } \\
\text { already been told what to think. } \\
\text { After all, we wouldn't want them to think for themselves. That would } \\
\text { be bad, wouldn't it? }\end{array}$ & $\mathrm{T} 4$ & $11 / 19 / 2018$ \\
\hline 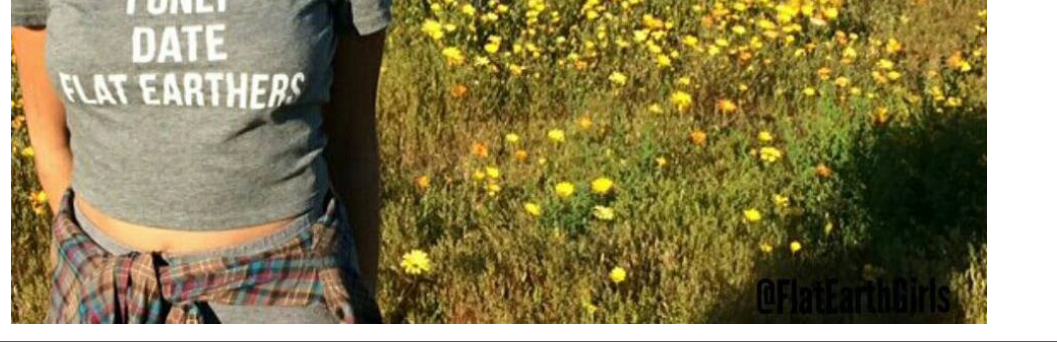 & T5 & $12 / 11 / 2018$ \\
\hline $\begin{array}{l}\text { An entirely fabricated space exploration industry. } \\
\text { \#WeirdPlacesToHideMoney }\end{array}$ & T6 & 01/10/2019 \\
\hline $\begin{array}{l}\text { \#INeverLearnedHowTo blindly and unquestioningly follow } \\
\text { propaganda. Damn. }\end{array}$ & T7 & 01/11/2019 \\
\hline $\begin{array}{l}\text { People's instinctive reaction to confrontation is to engage in fight-or- } \\
\text { flight behavior. Evolutionarily, this is well justified, but that sort of } \\
\text { siege mentality is unhelpful to modern discourse. }\end{array}$ & T8 & $04 / 12 / 2019$ \\
\hline
\end{tabular}

Figure 1. The analytical corpus

Source: Flat Earth Society Twitter page 
Direct language, as well as sarcasm, are notable features in the page's publications and denoted in tweets T2 and T3. In these, by means of short phrases, the page claims, in T2, that "\#EverybodyShouldGet informed on the simple fact that the Earth is flat", and in T3, that merely "The Earth is not round". This short structuring of the phrases, in addition to the use of a hashtag, a tool used for indexing posts on social media, denote the intention of Flat Earth Society content creators to disseminate their ideas widely, implying that people are not well informed about the topic and should rethink what they are believing. These characteristics appear in the phrases: "If found (the curvature of the Earth), contact EVERYONE" contained in the "meme" of T1; "\#EverybodyShouldGet informed [...]", contained in T2, and "\#StartOverIn5Words", contained in T3.

In these cases cited, the need for promoters of the Flat Earth Society page to exemplify discursive consolidation in the face of possible segregation imposed on them by public opinion and institutionalized science can be exemplified. As part of a group negatively labeled in the public debate - the merit of this is not being questioned here -, in their publications about flat Earth, there is a search for the affirmation of their discourses, as well as the search for demoralization of the authority of Science as a means of assertion of its flat Earth theses. This is an occurrence already debated by Harambam and Aupers (2014), according to which this does not necessarily point to an affront, at any cost, to modern Science, but indicates a kind of search for 'purification' of what, according to them, would be the free and non-dogmatic spirit of investigation in the world.

This type of ambiguous behavior towards science can be reiterated by T8. In this, the page questions the reactive way in which, in supposition, people tend to act in response to the theses of the flat Earth, assuming, according to the page, behaviors of fight or flight in relation to ideas opposite to what they know. The page also indicates that such reactive behavior has evolutionary justifications, in addition to being, as they maintain, useless to the discourse of modern Science. This ambivalence in the face of scientific knowledge, in terms of criticism of a type of authoritarian stance by certain scientists, can be equated with the very criticism that Feyerabend (1977) promoted regarding skepticism in Science. For this author, such skepticism:

[...] is minimal; it is directed against the opponents' way of seeing and against secondary ramifications of the fundamental ideas that are defended, but it never rises against the basic ideas themselves. Attacking basic ideas arouses taboo reactions that are no less intense than taboo reactions in so-called primitive societies. Basic beliefs are protected by this reaction and, as we have seen, by secondary elaborations; and everything that fails to accommodate itself to the established system of categories is declared incompatible with that system or is seen as something scandalous or, more often than not, is simply considered to be non-existent (Feyerabend, 1977, p. 452, italics by the author, our translation).

In addition to the attack on basic ideas by a Science with authoritarian potential, at least when acting on the parameters mentioned, Feyerabend (1977) also talks about 
the practice, by Science, of demoralizing discourses that do not fit the current hierarchy, and become stigmatized in the public debate. According to the author:

It is not said that some people believe that the Earth moves around the Sun, while others consider that the Earth is a hollow sphere, containing the Sun, the planets, the fixed stars. It is said: the Earth revolves around the Sun - and everything else is pure idiocy (Feyerabend, 1977, p. 459, italics by the author, our translation).

At this juncture, for Feyerabend (1977), these mechanisms of segregation, which start from the attack on basic ideas and the demoralization of opponents, would function as ways of affirming the scientific theories themselves, without which it would be impossible to have the establishment of modern Science. This demoralization of the rival discourse, either by attacking basic ideas or by the stigmatization of the speakers, can be similar to the exclusion principles on which Foucault (1996) spoke about. Among them, the separation between reason and madness and between true and false can be highlighted. Regarding the first principle, the author comments:

Since the Middle Ages, the madman has been the one whose speech cannot circulate like that of others: it may happen that his word is considered null and is not accepted, having neither truth nor importance [...]. It was through his words that the madness of the madman was recognized; they were the place where separation took place; but they were never collected or heard (Foucault, 1996, p. 11, our translation).

For the author, qualifying a discourse as linked to madness has always been a means of segregating the subjects who utters it, an occurrence that still remains active in society. Nowadays, this has occurred by other means and in other ways, but with the same intention of separation, similarly to another principle of exclusion that the author calls the will to truth.

Now, this will to truth, like other exclusion systems, is based on institutional support: it is at the same time reinforced and renewed by a whole compact set of practices such as pedagogy, of course, like the book system, of editing libraries, like the societies of sages in the past, laboratories today. But it is also reappointed, more deeply without a doubt, by the way knowledge is applied in a society, how it is valued, distributed, shared and in a certain way attributed [...]. Anyway, I believe that this desire for truth, thus supported by institutional support and distribution, tends to exert on other discourses - I am always talking about our society - a kind of pressure and as a kind of coercive power (Foucault, 1996, p. 18, our translation).

In this context, it can be considered that the need for affirmation and the provocative tone, characteristic of the Flat Earth Society tweets, portray a kind of reaction of the promoters of the page to the discursive segregation suffered by 'flat Earthers', in face of the predominance of the scientific discourse, at least in this scope. It can also be seen as an attempt at discursive consolidation in the face of the negative and stigmatized qualifications they receive, considerations that can be supported by what Harambam and Aupers (2014) discussed about the search, by conspiracy groups, for contesting the epistemic authority of Science. 
It should be made clear, based on these theoretical approaches, that it is not our intention to question the legitimacy of the establishment of scientific discourse, nor to suppose that conspiracy discourses can have theoretical coherence and, in hypothesis, more space in the public debate. As Latour (2004) points out, when analyzing a controversy from a symmetrical point of view like this, without qualifying the subjects involved as winners and losers beforehand, we always run the risk of being judged as enemies of a Science at risk, or having our speeches co-opted by subjects who use them to attack things we appreciate.

Knowing about this risk, the option to sustain this discussion, in these terms, occurs with the intention of avoiding, as pointed out by Stengers (2015), the confrontation as confrontation, and ending, as the author says, proposing certainties without experiencing the experience of perplexity. Apart from this, the issue we propose to discuss is more in line with the understanding of the cultural and discursive complexity of belief in conspiracies, which can be associated with several factors, among them, motivational issues and the need for exclusivity, highlighted by Lantian et al. (2017). Such factors go beyond the demand for the mastery of scientific knowledge, based on standards of rationality, as highlighted by Browne et al. (2015).

This cultural complexity, linked to the belief in conspiracies, can be verified by analyzing certain arguments present in tweets T4, T6 and T7. In addition to opposing the scientific knowledge established about the shape of the Earth, there are also criticisms regarding: the supposed ideological indoctrination promoted by the school system, in the first tweet; the application of scientific knowledge by the space exploration industry and the large volume of money involved, in the second tweet; as well as the alleged misleading advertising promoted by Science in the dissemination of its theories, in the third tweet.

Much more than a defense of the Flat Earth hypothesis, this thematic diversity, present in the tweets on the page, seems to denote a tendency for conspiracies to consolidate as a monological system of beliefs, as discussed by Goertzel (1994) and Wood, Douglas and Sutton (2012). Such a system is driven not by the relationship between different conspiracies and their particular theorizations, but by the coherence between each conspiracy and a higher order belief about the world, which is almost always a strong feeling of distrust towards certain institutions or groups of people. This situation would support the fact that the same person can believe and support different conspiracies that are contextually disconnected and even contradictory to each other, because what would be connecting them would be the central feeling of distrust and not the logic of their hypotheses in particular.

In discursive terms, this trend of thematic diversity, present in the tweets of the Flat Earth Society page, refers to the heterogeneity of the discourse on which Foucault (1986) dissertates. This means considering the formation of discourses as an articulated system, or, as Fischer (2001) argues in relation to Foucault's conception of discourse in an educational context, an open space of divergences and oppositions, in which: 
[...] discursive formation is made of roughness and stridency, rather than harmonies and smooth surfaces. Entirely alive, the enunciative field welcomes news and imitations, homogeneous blocks of utterances, as well as disparate sets, changes and continuities. Everything in it intersects, establishes relationships, promoting interdependencies. What is dissonant is also productive, what sows doubt is also critical positivity (Fischer, 2001, p. 210, our translation).

To think about this discourse, in this context, is to consider the generalized mistrust in relation to scientific knowledge as the very condition of the possibility of the 'flat Earther' discourse, since it is the disagreements with Science that support its production of statements. Those that, for Foucault (1986), are neither neutral nor independent, but constituents of a network in which each individual statement plays a role among others, in this field of coexistence. Such facts help us to understand the posts promoted by the Flat Earth Society page as representations of these statements, which is in line with the discussions carried out by Goertzel (1994) and Wood, Douglas and Sutton (2012) about conspiracies constituting themselves as a system of monological beliefs.

What can be remarked from this conjuncture is that, as highlighted by Feyerabend (1977), the segregation of rival discourses is what gives scope to the establishment of Science in society, an assumption that can be associated with what Foucault (1996) approaches in relation to the institutionalization of the discourse exclusion principles discussed here. In confrontation with this, possibly due to a reaction to this segregation, the generalized mistrust in relation to Science can be considered the condition for the establishment of conspiracy discourses such as that of the flat Earth. Such discourses seek foundation through the diversification of themes which seek to oppose Science, not being tied only to their 'flat-Earther' hypotheses, but consolidating themselves as part of a broad system of beliefs.

On the other hand, when it comes to the dissemination of their 'flat-Earther' hypotheses on social media, the heterogeneity in the formation of discourses, within the scope of which Foucault (1986) discusses, has as one of its effects the propagation of struggles of subject co-optation. With this plurality, what is increasingly at stake is a "struggle for the imposition of meaning, the struggle between various discourses, in the conquest of new subjects" (Fischer, 2001, p. 212, our translation). In this context of dispute over the media, it should be noted that:

[...] if each discourse is sent by itself to so many others, the discourses incorporated by the media, from other fields - especially those of medicine, pedagogy, psychology, psychoanalysis -, also, when they enter the media scene, when taking form within that specific field of social communication, undergo a treatment that removes them from their habitat and, at the same time, reinforces each one's own authority [...] (Fischer, 2012 , p. 214, italics by the author, our translation).

This situation also seems to be valid for conspiracies such as of the flat Earth. When it comes to the social media environment, these subjects can disseminate their discourss without suffering, at least directly, by the institutionalized segregation 
discussed by Foucault (1996). This is because they are free to post and share their ideas, as long as they do not violate certain rules and policies imposed by the platform. This environment therefore represents a powerful means by which they can reinforce their critical theses to Science and co-opt more subjects interested in their explanations, even if, in certain cases, being controversial when using their own scientific knowledge for this, as occurs in $\mathrm{T} 8$.

In this context, the production and sharing of 'flat-Earther' content on social media through the Flat Earth Society page is the representation of the practical formation of its discourse. This is in line with Foucault's (1996) discursive perspective and goes beyond the particular theories that aim to undertake, establishing themselves as part of a broader discursive network than these particular discourses would mean. These discussions lead us to hypothesize that the search for exclusion from these discourses, as well as the forced attempt to change based on absolute standards of rationality, in addition to being undesirable in democratic contexts of freedom of expression, are, in short, inconsistent with the the very discursive formation of these groups, which have in their confrontation with Science their creative condition and in the challenge to scientific authority a means of reaction to the segregation imposed on them ${ }^{2}$.

That said, what this panorama raises is to seek an understanding of the actions of 'flat-Earther' groups, as in the case investigated, as well as the cultural complexity to which they are immersed, rather than, beforehand, establishing univocal solutions in the face of the expansion of their theses in society. On the other hand, these considerations do not lead us to say that there is nothing to be done. On the contrary, the very proposition of strategies, in the face of the expansion of beliefs like these, reckless for educational and scientific contexts, needs to be based on the consideration of the cultural and discursive complexity of these beliefs and not just immediate assumptions of demand for the domain of scientific knowledge.

Finally, in view of this investigative movement carried out and whose results we have exposed here, some possible considerations could be proposed, in order to close this first part of the research (others are in progress).

\section{Possible considerations}

At the end of a research that sought to analyze publications considered 'flatEarthists', originated from a social media page, taking theoretical analysis perspectives from Foucault (1996), Feyerabend (1977; 2010), Latour (2004; 2011), Fischer (2001), among others, some considerations could be produced, in an attempt to answer the guiding questions proposed: From these perspectives, what understandings could be demonstrated from the discourse evidenced in the analyzed Twitter publications, considered 'conspiracists' and that claim that the Earth is flat? What positions could the field of Science Education put together in the face of these discourses?

2 The merit of this imposition is not in question, but only that this discursive segregation is what motivates such reactions. 
With regard to the first question, the discussions carried out make it possible to conjecture that the formation of conspiracy discourses, such as those that affirm that the Earth is flat, has as its own creative condition the mistrust of Science, although with a certain ambiguity of intentions, as noted by Harambam and Aupers (2014).

In this sense, in face of the institutionalized authority of Science in society, which has already been discussed by Feyerabend (1977), and in line with the discourse exclusion principles highlighted by Foucault (1996), 'flat Earth' groups, such as the one investigated here, have responded to that authority as a means of asserting their own discourses. This leads us to consider that the justifications for such reactions are not only linked to a probable demand for mastery of scientific knowledge, but, as we have discussed, they are constituted as ways of discursive affirmation and of strengthening one's own hypotheses. This does not mean to conjecture that 'flat-Earthers' do not present urgencies due to mastery of scientific knowledge or due to evidence-based reasoning, but only that these are not, perhaps, the only and perhaps fundamental foundation of the formation of their discourses.

In this sense, as part of the discursive affirmation process, these groups have sought to broaden their discussion themes, not only being subordinate to their 'flat Earth' hypotheses, but also criticizing the current school system, the application of scientific knowledge by the space industry, as well as the process of scientific dissemination in society, as evidenced in the analysis of T4, T6 and T7. Thus, such groups are part of an articulated discursive network (Foucault, 1996), characterized by heterogeneity in the production of statements that support the formation of their discourse. Such an assumption that can be assimilated to the discussions promoted by Goertzel (1994) and Wood, Douglas and Sutton (2012) regarding the characteristic of conspiracies constituting a monological system of beliefs, which has, in the generalized mistrust in relation to Science, its aggregator medium. In addition to the discursive formation, the explanation through a page on social media also highlights the search for discursive strengthening and for the co-optation of more subjects, as part of a game of "struggle for the imposition of meaning, the struggle between various discourses, in the conquest of new subjects"(Fischer, 2001, p. 212, our translation).

This allows us to conjecture on the second of the guiding questions: given the cultural and discursive complexity linked to conspiracies, conceiving that the coercion of theoretical conspiratorial exposures in media can contribute to their interdiction is both a dogmatic and potentially naive action. Dogmatic because, as pointed out by Feyerabend (1977), it would start from the attack on the way of seeing the world of opponents, thus not being appreciated and understood, the entanglement in which these conspiracies and their attitudes of denial of Science are submitted, constituting a wide and heterogeneous system of beliefs. Naive because the primordial condition for the establishment of these discourses is not, perhaps, the rational assessment of facts related to the determined controversy, but rather the mistrust of Science. In this way, to expect that the conspiracists' followers fail to defend their ideas, when confronted, would be to 
trust that they would renounce their own condition of speaking, and that they would not seek other means of action if coerced.

This assumption leads us to the understanding that the proposition of containment strategies, on the part of the Science Education field, in the face of the expansion of conspiracies like these in their active contexts, does not need to be guided by a frontal opposition. According to Stengers (2015), this practice should be avoided in the processes surrounding a controversy, since it "empties the world and only the two visibly opposed fields remain, one functioning in reference to the other" (Stengers, 2015, p. 131, our translation). In addition, it is necessary to understand these conspiracies in their cultural and discursive complexity, which would offer subsidies to conjecture, as Harambam and Aupers (2014) also indicate, about how and why these groups have resisted and fought the institutionalized authority of Science. As these authors said, there is an ambiguity in the positioning of conspiracy groups in relation to Science, which is sometimes sacralized for its intentions, or sometimes demonized for its means of institutionalization. In this sense, the frontal opposition, instead of helping to understand this ambiguous positioning, "threatens to give answers before having learned to ask questions, proposing certainties before having experienced the perplexity" (Stengers, 2015, p. 27, our translation).

These considerations open room for expanding the investigative paths of the Science Education field itself, which will require, in these terms, the help of theories and techniques from other areas of knowledge, including Psychology, Psychiatry, Anthropology and Sociology, in order to cover this discussed complexity, so that the strategies to deal with such conspiratorial beliefs can be established in a solid way in theoretical and methodological terms. It was not our intention (in this investigative movement) to present practical solutions or methods to deal with these conspiracies, an intention that is in line with the referentials used here. However, we hope that the discussions promoted can support the development of more research on this topic, consolidating it as relevant and fruitful for Science Education.

\section{References}

Bardin, L. (2011). Análise de conteúdo. Edições 70.

Browne, M., Thomson, P., Rockloff, M. J., \& Pennycook, G. (2015). Going against the herd: psychological and cultural factors underlying the 'vaccination confidence gap'. Plos One, 10(09), 1-14. Retrieved from https://doi.org/10.1371/journal.pone.0132562

Douglas, K. M., Sutton, R. M., Mitchell J. C., Rael, J. D., \& Annelie J. H. (2016). Someone is pulling the strings: hypersensitive agency detection and belief in conspiracy theories. Thinking \& Reasoning, 22(1), 57-77. Retrieved from http://dx.doi.org/10.1080/1354678 3.2015.1051586

Dunker, C., Tezza, C., Fuks, J., Tiburi, M., \& Safatle, V. (2017). Ética e pós-verdade. Dublinense. 
Feyerabend, P. (1977). Contra o método. Francisco Alves.

Feyerabend, P. (2010). Adeus à razão. Editora Unesp.

Fischer, R. M. B. (2001). Foucault e análise do discurso em educação. Cadernos de Pesquisa, São Paulo, (114), 197-223. Retrieved from http://dx.doi.org/10.1590/S0100

Foucault, M. (1996). A ordem do discurso (3a. ed.). Edições Loyola.

Foucault, M. (1986). A arqueologia do saber. Forense.

Goertzel, T. (1994). Belief in conspiracy theories. Political psychology, 15(4), 731-742. Retrieved from https://doi.org/10.2307/3791630

Harambam, J., \& Aupers, S. (2014). Contesting epistemic authority: conspiracy theories on the boundaries of science. Public understanding of science, 24(4), 466-480. Retrieved from https://doi.org/ 10.1177/0963662514559891

Jolley, D., \& Douglas, K. M. (2014). The effects of anti-vaccine conspiracy theories on vaccination intentions. Plos one, 9(2), 1-9. Retrieved from https://doi.org/10.1371/ journal.pone.0089177

Lantian, A., Muller, D., Nurra, C., \& Douglas, K. M. (2017). I know thing they don't know: The role of need for uniqueness in belief in conspiracy theories. Social Psychology, 48(03), 160-173. Retrieved from https://doi.org/10.1027/1864-9335/a000306

Latour, B. (2004). Why has critique run out of steam? From matters of fact of matters of concern. Critical Inquiry, 30(2), 25-248. Retrieved from https://doi.org/10.1086/421123

Latour, B. (2011). Ciência em ação: como seguir cientistas e engenheiros sociedade afora (2a. ed.). Editora Unesp.

Pelkmans, M., \& Machold, R. (2011). Conspiracy theories and their truth trajectories. Focaal - Journal of global and historical anthropology, (59), 66-80.

Prooijen, J. W. V., \& Douglas, K. M. (2018). Belief in conspiracy theories: basic principles of an emerging research domain. European journal of social psychology, 48(7), 897-908. Retrieved from https://doi.org/10.1002/ejsp.2530

Prooijen, J. W. V. (2015). Sometimes inclusion breeds suspicion: self-uncertainty and belongingness predict belief in conspiracy theories. European journal of social psychology. 46(3), 267-279. Retrieved from https://doi.org/10.1002/ejsp.2157

Prooijen, J. W. V. (2017). Why education predicts decreased belief in conspiracy theories. Applied cognitive psychology, 31(1), 50-58. Retrieved from https://doi.org/10.1002/ acp.3301

Prooijen, J. W. V., \& Douglas, K. M. (2018). Belief in conspiracy theories: basic principles of an emerging research domain. European journal of social psychology, 48(7), 897-908. Retrieved from https://doi.org/10.1002/ejsp.2530 
Shifman, I. (2013). Memes in a digital world: reconciling with a conceptual troublemaker. Journal of computer-mediated communication, 18(3), 362-377. Retrieved from https:// doi.org/10.1111/jcc4.12013

Silva, B. C., Vegetti, F., \& Littvay, I. (2017). The elite is up to something: exploring the relation between populism and belief in conspiracy theories. Swiss political science review, 23(4), 423-443. Retrieved from https://doi.org/10.1111/spsr.12270

Stengers, I. (2015). No tempo das catástrofes: resistir à barbárie que se aproxima. Cosaf Naify.

Swami, V., Voracek, M., Stieger, S., Tran, U. S., \& Furnham, A. (2014). Analytic thinking reduces belief in conspiracy theories. Cognition, 133(3), 572-585. Retrieved from https:// doi.org/10.1016/j.cognition.2014.08.006

Wood, M. J. (2016). Some dare call it conspiracy: labeling something a conspiracy theory does not reduce belief in it. Political psychology, 37(5), 695-705. Retrieved from https:// doi.org/10.1111/pops.12285

Wood, M. J., Douglas, K. M., \& Sutton, R. M. (2012). Dead and alive: beliefs in contradictory conspiracy theories. Social psychological and personality science, 6(3), 767-773. Retrieved from https://doi.org/10.1177/1948550611434786 


\section{Leonardo Wilezelek Soares de Melo}

${ }^{\oplus}$ https://orcid.org/0000-0002-4243-4216

Universidade Estadual de Londrina Programa de Pós-Graduação em Ensino de Ciências e Educação Matemática Londrina, Paraná, Brazil leonardowdemelo@gmail.com

Marinez Meneghello Passos

(1) https://orcid.org/0000-0001-8856-5521

Universidade Estadual de Londrina

Programa de Pós-Graduação em Ensino de Ciências e Educação Matemática Departamento de Matemática/CCE Londrina, Paraná, Brazil marinezmp@sercomtel.com.br

Rosana Figueiredo Salvi

[1] https://orcid.org/0000-0001-9475-9867

Universidade Estadual de Londrina

Programa de Pós-Graduação em Ensino de Ciências e Educação Matemática Departamento de Geociências/CCE Londrina, Paraná, Brazil ro06salvi@gmail.com

Submitted on 26th February 2020 Accepted on 09th April 2020 Published on 01st May 2020 